\title{
Locus of control, interest in schooling and self-efficacy as predictors of academic identity in an academic community of practice
}

\author{
Charles Adedayo Adebanji \\ Midrand Graduate Institute, South Africa
}

\begin{abstract}
This research set out to explore how French-speaking students (FSS) construct and negotiate their academic identities in a multiculturally contrasting academic milieu. Academic identity is described as academic self-esteem because it is required by students to take responsibility for their learning. It is a stipulation of communicated and negotiated trajectories of experiences that depict how people see themselves and how they are seen by others(Vandeyar, 2010). The negotiation of identity requires diverse dimensions of engagement with more knowledgeable others (MKO) (Reyes, 2007) in communities of practice (Wenger, 1998). Utilising the research strategy of narrative inquiry, case study, semistructured interviews, and focus group interviews, this paper explores how FSS perceived themselves in relation to how they took responsibility for their learning. It is argued in this paper that the development of the necessary academic self-esteem via the acquisition of locus of control, interest in schooling and self-efficacy can assist foreign students to take responsibility for their learning without having feelings of prejudice as they engage with MKO in academic communities of practice. The paper will conclude by suggesting that academic institutions can utilise engagement,devoid of discrimination as a tool to minimise dropout.
\end{abstract}

Key words: Locus of control, Interest in schooling, Self-efficacy, Communities of practice, academic identity.

\section{Introduction and background context}

This paper explores the reconstruction of academic identity among FSS from African countries by considering three major constructs namely, locus of control (LOC), interest in schooling and self-efficacy. These three constructs are linked to the negotiation of identity by extrapolating the constructs in termsof how they impact on their self-esteem, otherwise referred to as academic identity. French-speaking students travel abroad to learn in English, in an attempt to be bilingual and to meet up with the demands of globalisation (Adebanji, 2013). Prior to studying abroad it is assumed that they had academic identities which enabled them to negotiate academic concerns in their usual countries of origin. Travelling abroad to study in another language is hypothesised to necessitate a reconstruction of academic identities among them. Academic identity lays emphasis on the fabrication of academic self-esteem,required to take responsibility for learning and how people perceive themselves in the midst of others.Self-esteem, according to Leung (2010) is one of the socio-emotional aspects of life. Socio-emotional aspects of life are interpreted as the aftermaths of interaction with dissimilar cultures in this paper. The other features of socio-emotional dynamics include peer association and interpersonal association (Leung, 2010). I take up the challenge noted by Leung $(2010,23)$ that researchers "seldom focus on socio-emotional aspects, such as self-esteem, peer affiliation, and inter-personal relationships" to explore how the FSS reconstruct their academic identities in a private higher education institution of South Africa (SA). The rationale for exploring this study hinges on the knowledge that foreign students arrive to an unusual academic culture with their cultural capital, confronted by the dilemma of how to adjust to new scholastic cultures on the ground(Reynolds \& Constantine, 2007). According to Brown (2008) the enormity of assignments, linguistic challenges and scholastic cultural dissimilarities place foreign students under intense pressure. These culminate in a displeasing dimension of association with indigenous students, particularly when they newly resume at the institution.Apart from these challenges, differences have been found between high-and-low accomplishing students in diverse concepts, such as academic self-esteem, attitude, and international self-esteem. Consequently I will be contemplating academic identity by exploring peer association and interpersonal relationships in scholastic dimensions. Studies suggest that reassuring self-esteem is capable of enhancing desirable academic performance (Chapman, 1988; Marsh, Bryne \& Yeung, 1999). The implication of this submission on this study entails exploring the impact that academic self-esteem development has on the FSS. These moorings in the voluminous literature predispose this paper to exploring the academic identities of FSS in a multiculturally diverse academic community of practice with lecturers acting as experts and the students as newcomers. Studies have shown how academics negotiate their identities in SA (e.g. Vandeyar, 2010). Vandeyar (2010) elaborately discussed issues about "shifting selves" and the negotiation of identities in academia.She came up with very 
insightful expositions, arousing my interest to explore how FSS negotiate their academic identities and the impact this may have on their learning trajectories. She argues that the lived and related anecdotes of academics highlighted the assortment of their identities that were transacted with associates within particular, historic and circumstantial milieus. These academics comprised communities of practice with offerings to share, gain or lose. Of importance to the academics explored by Vandeyar (2010) was how they perceived themselves in relation to their colleagues and their historic, specific and contingentexperiences. Wenger $(1998,163)$ sees academic identity as an association comprising many stakeholders because identity integrates diverse patterns of associations via the path of compromise across frontiers of practice. These issues suggest that academic selfesteem is a construct that requires membership in diverse communities of practice (COP) and it could take actors having the effrontery to initiate negotiation via the route of compromise in order to take the required stance to acquire the self-esteem they need.It is not common to find studies revealing how FSS negotiate their academic identities in the private tertiary institutions of SA. A lot is being done on the negotiation of identity by immigrants in SA. Equipped with the aforementioned, this paper asks how FSSreconstruct their academic selfesteem and how it affects their affiliation with peers in a multiculturally disparate academic community of practice (ACOP).I use the word "reconstruct" because they previously had academic identity in their usual countries of sojourn. In order to fit into a new terrain, they are required to renegotiate their academic identitiesin order to take responsibility for learning. The intellectual predicament is tackled in the following manner: First, I initiate a discussion to furtherlocate the paper in the voluminous literature on the three identified constructs namely, LOC, interest in schooling and self-efficacy. An additional theoretical framework that ascribes meaning to the experiences of FSS in terms of how they develop academic self-esteem is heralded. This is discussed as an adjunct to the three models namely LOC, interest in schooling and self-efficacy. Third, the research methodology is discussed. Fourth, the findings are presented. Fifth the discussion on the findings is presented. Last, conclusions are drawn and recommendations are made.

\section{Theoretical architecture}

Identity is a construct ofpositioned experiences that are negotiated by people (Owens, 2003). It is a non-static phenomenon, informed by history and an assortment of experiences in an environment of influence (Vandeyar, 2008). In this review attention shall be given to what I refer to as particularity or exactitude, locus of control (LOC), interest in schooling and self-efficacy. Particularity, as it applies to this study has to do with individuals concerned with certain enterprises of choice and action within a specified realm of operation. Particularity appears to me as an index of identity, based on situated experiences that are triggered by the earnestness to triumph over scholastic challenges. In an attempt to situate this intellectual puzzle in the voluminous literature, I take a stance by categorically asserting that issues bordering on particularity, LOC, selfesteem, and interest in schooling are circumscribed by the construct of identity.

\section{Locus of control}

Individual experiences appear to be governed by what the literature refers to as the locus of control (Njus \& Brockway, 1999). Locus of control (LOC) is an individual's opinion on the grounds of his/her involvements and the dynamics to which that individual ascribes success or failure (Njus \& Brockway, 1999). According to Zimbardo $(1985,275)$, a locus of control "is a belief about whether the outcomes of our actions are contingent on what we do (internal control orientation) or on events outside our personal control (external control orientation)." As far as the FSS are concerned, their opinions on the grounds of their involvements in the academic institution, and the dynamics to which they ascribe success or failure would be taken as emblems of their academic identities. LOC can be internal or external, according to Rotter (1966). Individuals in possession of internal LOC ascribe success to their individual determination and capabilities. It implies that such individuals will be devoted to the tenets of learning to attain an identity. If the FSS are committed to the principles of learning to attain an identity and they succeed, they would be regarded as having internal LOC. When they are in possession of internal LOC they would be taken to have positive academic identities or positive academic self-esteem. An individual with internal LOC will therefore deliberately look for details on how to conquer challenges with optimistic scholastic approach. Taking responsibility for one's learning is regarded as theaspiration to attain an identity, a symbol of internal LOC. Conversely, an individual with an external LOC will always ascribe his/her success to good luck or chance and will not likely be determined to learn (Teller, Teller \& Adeyemi, 2011), a demonstration of low academic self-esteem. The development of academic self-esteem is conceptualised to depend on internal and external LOC. I intertwine the LOC concept with adeptness to learn and the negotiation of identity. Adroitness to learn therefore has an undertone of identity construction because the motivation to take ownership of learning is an intrinsic aspect of taking responsibility to attain an identity. The FSS will be regarded as having internal LOC if they put in an effort to take responsibility for their learning and they succeed in learning. This conscious effort becomes the choice they have made, an undertone that addresses their quest to have self-esteem in academic matters. The FSS will be 
seen as having external LOC if they are non-challant about taking responsibility for their learning. Consequently they would be seen as having low academic self-esteem and this reflects via their demonstration of scholastic redundancy.

\section{Interest in schooling}

Interest in becoming educated, otherwise referred to as interest in schooling is borrowed as a concept to decipher how FSS develop academic identity. Interest in schooling is conceptualised in this paper as an enhancerof academic self-esteem. I take solace in Adeyemo's (2005) statement that "the importance of interest in whatever a person does cannot be underestimated (166)." This statement seems imperative because "when it comes to making choice, interest is of considerable importance." (166). Choice itself is an emblem of identity negotiation, drawing on Kohn who argues that "identity is all about choice, action and a multiplicity of experience and allegiance" (Kohn, 2002, 155).Two realms of interest have been identified by Hiddi and Anderson (1992) as personal and situational interests. Personal interest (PI) is an indication of the interest brought into scenarios by people. Situational interest (SI) pertains to the interest gathered as people participate in a specified activity. As far as this paper is concerned, the two are relevant to establish how the FSS developed academic identities. An exhibition of PI would imply that the FSS are motivated to willingly pursue scholastic enterprise in an attempt to develop academic self-esteem. Similarly if they are motivated to develop interest by virtue of the situation they meet on the ground, they would also be seen as developing what I refer to as situational academic self-esteem. Renninger (2000) notes that "people working with individual interests are motivated learners", because 'their activity appears purposeful, sustained, and ever deepening; they do not really need to make a choice to learn subject matter that is of individual interest to them" (p.19). Reninger points to the relevance of fabricating self-esteem by actors when the interest to do so is present. PI thus makes participation to become spontaneous because they are not confronted by having to consider any scale of preference in order to belong. The implication of this scholarship on the current paper is that the exhibition of PI by the FSS to study in an unusual culture would be taken as motivation to attain an identity which is tantamount to positive academic self-esteem.PI thus becomes a forerunner of academic self-esteem construction.

Of utmost importance in the exploration of interest in schooling as a yardstick for predicting the cultivation of academic self-esteem is the school environment. The prominence of the school vicinity is based on the socio-emotional perspectives of students operating within the school context. It therefore means that their perceptionofhappeningsin the school environment and their responseto such happenings counts in their development of academic self-esteem, drawing on Adeyemo (2005). The school environment, according to Adeyemo (2005) impacts on the conduct and growth of individuals. Therefore the school vicinity comprises both the psychosomatic and somatic dimensions, and these two dimensionsexertequal effect on each other. The relationship that the FSS experience with stakeholders in the academic institution is implied to impact on their academic self-esteem. A pleasant relationship with stakeholders is predicted to impact on their psychosomatic experiences and this could enhance the development of positive academic self-esteem in them.

\section{Self-efficacy}

The concept of self-efficacy emanates from Bandura (1986) as a key component of the social cognitive theory (SCT). Self-efficacy is the confidence acquired by an individual to successfully complete a task. It is a theory on its own, a paradigm of the SCT. Self-efficacy theory (SET) informs us that humans will usually perform tasks that they are confident to achieve and would not dare to do tasks they feel they are incapable of achieving. On the other hand, humans with a resilient sense of efficacy are bold to undertake uneasy tasks. They see challenges as steppingstones to success instead of oppositions to be avoided (Bandura, 1997). In 1997 Bandura stretches the frontiers of the SCT to include self-efficacy as a driver of academic achievement. This paper extrapolates self-efficacy to denote the capacity of students to take responsibility for their learning to succeed. Ipostulate that the capacity of students to take responsibility for their learning is a symbol of their academic self-esteem. The definition of self-efficacy, proposed by Shell, Bruning and Colvin (1995) has been identified fit for understanding the development of academic self-esteem by FSS. Shell et al. (1995) defines selfefficacy as self-assurance in one's capabilities to effectively execute a specific undertaking.I see in this definition that it takes having self-esteem to be able to perform any academic task in communities of practice. The reason is that the effrontery to interact with MKOseems to require the ability to step beyond personal territorial jurisdiction, especially in the absence of prejudice. Despite the diverse dimensions that self-efficacy addresses (Bandura, 1997), it shall be discussed in relation to the development of academic identity. Schunk's (1991) definition of self-esteem seems to suit academic discourse because it addresses an individual's apparent capacity and motivation to carry out assigned scholastic tasks in the desired perspective.Hawthorne (2004) seems to corroborate my conceptualisation of academic identity development by arguing that students in possession of self-efficacy adopt self-regulation in their studies in an attempt to enhance their academic achievement. I also hinge on Zimmerman's (2000) submission that self-efficacy is positively linked to 
motivation. It would therefore imply that motivation to succeed and achieve academically among the FSS point to their development of academic identity.

\section{Communities of practice}

I adopt the communities of practice (COP) framework (Wenger, 1998), in consonance with the abovementioned models to further propose an explanation of how the FSS develop academic identity. The environment of the tertiary institution is conceptualised as an ACOPbecause lecturers facilitate learning via interaction to students under the tenet of cooperative learning, drawing on Otten (2009). According to Wenger's (1998) suggestion COP are groups of individuals who partake in a concern or a craving for what they do, and who work together frequently to learn how to perfect what they do. The FSS in this research are regarded as new entrants because they are in an academic environment, disparate from the ones in which they were previously educated. Within this milieu, the development of self-esteem typifies a perpetual communal compromise that can be comprehended via the activities in which the FSS participate. Therefore as suggested by Wenger (1998), actors' dealings with dissimilar COP construct prospects for identities to be simultaneously creative and controversial. In this paper, the dealings of the FSS with stakeholders is deemed creative when they are in possession of academic self-esteem because of its capacity to enhance focus on learning. On the other hand, controversial dealings with stakeholders would imply diminished self-esteem, an inclination of deterred learning.

\section{Research methodology}

I use constructivism and interpretivism, symbols of my epistemological perspective where a researcher conducts an investigation, and constructs knowledge from obtained data via the interpretive mode (Williamson, 2006, p.85). This study was qualitative and utilized narrative inquiry and case study of a private provider of higher education in the Gauteng Province of SA. The data gathering process comprised in-depth semistructured interviews, and lecture room observations over a period of one and a half years before the study was conducted. A thorough observation of the research site and participants was conducted to capture the scenery of the research site. A total of twenty-eight (28) FSS were purposively drawn from the pre-degree programme to the third-year degree programme. These comprised citizens of Cameroon, Gabon, the Democratic Republic of the Congo (DRC), Chad Republic and Benin Republic.

Additional data were collected in the first semester of 2013 at the research site via 2 focus group interviews with another cohort of FSS from the pre-degree to the third-year degree programmes. This action was embarked upon to support the previously collected data in 2012, to increase the depth of investigating this single case thus and enhance the validity of the study. A second round of semistructured interviews was conducted with the previously interviewed FSS on areas that were not covered in 2012. Many of the FSS who were admitted at the institution came in through the foundation programme and were prepared to meet the requirements of the degree programmes. The pre-degree programme also served as a period to enable the transition of FSS from French to English. Each interview lasted between 30 minutes to an hour, while the FSS were daily observed during lecture periods and in their informal sitting positions during free periods and as they went back to their residence. The interviews were video-recorded and transcribed to ensure analysis of obtained data. The data were analysed using content and thematic analyses methods as recommended by Elo and Kyngas (2008) and Braun and Clarke (2006) respectively. Ethical clearance was sought at the research site before the study was conducted.

\section{Findings}

The findings in this paper are presented in line with evidence that signifies the models namely LOC, interest in schooling and self-efficacy.

\section{Empirical evidence of LOC}

I present grounds of the involvements of FSS in the academic institution as evidence of their LOC. The following narratives showcase the reasons for their involvement in scholarly matters, indications of academic identity because they had self-worthas students of the academic institution. The following FSS responded to my inquiry on the reasons for belonging to the school and what constituted the grounds of their involvement. These narratives stemmed from the focus group interview session with them.

Onthatile: I like the way I was taught by my maths lecturer in pre-degree. The other lecturers too were very committed. The lecturers give me attachment to this school. I'm pleased with the courses that I am doing. Stephanus: I don't have any problem with this institution. I am happy to be here because most of the lecturers are very friendly. I prefer this place to the public university because they give us academic attention. 
October: This school is meeting my needs because our lecturers are kind. The mathematics lecturer pays attention to me in the class because he knows I am just trying to learn English. He knows me by name and calls me regularly to ask if I understand what he is saying. I am happy to be here.

Marthe: Although I am a few days old here, I like the environment of the school.

Rachel: Our lecturers are kind. In fact I am so lucky because they all love me so I feel at home here.

Cony: I am happy with this institution because we are not many in class. We have very good lecturers, although some of them may not be too good but I am glad to be here.

Violet: I like my mathematics lecturer. He is patient with us; I am encouraged by his presence at this school. He encourages me to work hard.

Small class size and personalised attention were found to constitute the basis on which some of the FSS developed academic identity. They compared the treatment given to them back home to their experiences at the private SA institution. I provide an example out of the cases that pointed to the issues of small class size and personalised attention in the following vignette.

Researcher: What gives you pride as a student of this institution?

Precious: This institution is better although it is a private institution. Back home, although I have never been to a private University but I guess it would be the same as it is here in this institution because in the private Universities, classes are smaller. If it is the public University, the crowd is usually too much. The lecturers don't actually take time to teach at the public universities because they are always under pressure.

The dynamics to which the FSS ascribe success or failure is another indicator of their possession of LOC. Satisfaction with academic life, library facilities and student-lecturer relationships comprised the basis on which a number of them had LOC. The following monographs reveal my interpretation of the dynamics of LOC.

Researcher: Would you say that you are satisfied with academic and social life at this institution?

Andre: Yes I am satisfied with the life here because, unless you come to this institution for any other reason other than to study then you would say that this school is not welcoming. But if your aim is to study here, there is a library where you can get the prescribed books. The lecturers are welcoming and any student can see them at any time and any student who wants to succeed would really love that. I can say I have adapted to the environment and the academic offering at this school.

Amanda's narrative supports the story of Andre on the dynamics to which FSS ascribe success or failure. She responds to my question thus:

Researcher: Do you have any role model at this school?

Amanda: There are actually two lecturers that I have admired throughout my stay at this institution. They are Mrs. Van Staden, the Head of the Faculty of IT (Information Technology) and MS Creek. For Mrs. Van Staden, I think about the way she teaches us in class and she handled the programming class in the first-year, and the way she explained matters. She explained and really motivated me to understand the concepts of programming and I like programming because the basis of programming was good. For Ms. Creek, I just like the way she teaches. I don't want to let them down. I wouldn't want to also let myself down.

I bring in Ornella's narrative to consolidate the narratives of the other FSS because of its insightfulness. She responds:

I enjoy the way we are taught at this school because this is not so in my country. In Gabon, if you don't understand something, the lecturer is not approachable. They tell students that their job is mainly in class and not outside the classroom. If you don't understand in class, it is your problem.

Beatrice's determination to succeed stems from the notion that there was no one with a university degree in her family and she was determined to steer opportunities in her direction to achieve:

I am determined to achieve my aim, and this is the means of doing it. Nobody has ever attended a university in my family. This institution is going to assist me to achieve my goal. I would rather use this opportunity wisely because I am comfortable with the way they teach students here.

Institutional dynamics constituted Zelda's development of academic identity because she began to see improvements in the modules that she was learning, an indication of prospects for success:

This institution is meeting my academic needs because I can see improvement in some of my modules. In Gabon, you can't approach the lecturers like here in South Africa because, they are very different. In Gabon when you are talking with a lecturer, people may think you are engaged or you are going out together. Also my South African friends help me to improve my English.

These were a few of the cases that indicated LOC. As far as this study is concerned, many of the FSS had internal LOC because of the determination they had to succeed. It was very rare to find those with external LOC because none of those interviewed had lackadaisical attitude towards learning.

\section{Empirical evidence of interest in schooling}

The abovementioned cases indicating LOC are similarly important as evidence of interest in schooling. However the following narratives point to vital attachments made by the FSS to the academic institution. These 
were points of attachment to study at the school. These narratives emanate from the focus group interview session and the question posed was to explore what motivated them to study in SA.

Caira: I prefer this institution because we are not many as in the public universities. The number of students in each class is small but I still prefer this institution.

Frida: I am proud to be a student of this institution.

Princess: I prefer this institution to the public institutions because we are not many in class.

Petunia: I enjoy the beauty of the school. The lecturers are very supportive and understanding.

Ennigrace: I like this school because I am making new friends who are helping me to learn English.

In the semistructured interview sessions conducted, the following were points of interest to study at the institution:

Belinda: I enjoy this school because there is no discrimination. My South African friends are welcoming. I enjoy living here because it is much hotter in my country (talking about the weather in South Africa, as better than in the DRC). The lecturers are very supportive. Student advisors offer assistance. The library is functional. I feel at home in this institution.

Miriam: I find that here, life is a bit easier than in my country. Life is very expensive in my country. I have met people who are very kind so I can fit into the society here. The people are helping me and my English is getting better and better everyday.

All of the FSS interviewed in this study came to SA to study in an attempt to be bilingual (personal interest). I present the narratives pointing to this claim. These were responses to my question to explore their intentions for studying in SA:

Researcher: Why did you decide to study in SA?

Erika: I am here because I want to learn and study in English because it is becoming a requirement to get jobs in Gabon.

Belinda: I came to study in SA because I want to study in English and not in French. Everywhere English is required. Even in my country, English is one of the required languages at school. It is also required to get jobs.

Zelda: I am in SA because I want to study in English because English is another important language apart from French.

It is obvious that different reasons account for the interest in schooling among the FSS. These ranged from small class size initiative, absence of discrimination, bilingualism, satisfaction with social and academic life, availability of friends who could teach them the use of English, to supportive student-lecturer relationships, to mention but a few.

\section{Empirical evidence of self-efficacy}

Andre's storyline portrays the scholarship of self-efficacy by Shell et al. (1995) that self-efficacy is self-assurance in one's capabilities to effectively execute a specific undertaking. As I chatted to him it was difficult to comprehend that he was not an original English speaker. I had to compliment him for speaking eloquently and he responded thus:

Thank you for that acknowledgment that my English is quite good. Yes I went to an English school for 10 months to learn English. I couldn't even greet when I got here six years ago. I actually worked on it. When I got here, I had to study in English. I am a dedicated person. When I am doing something, it is either I do it or I don't. When I do what I am supposed to do, I do it the way it is supposed to be done. That is the best I could do to speak the English I am speaking now.

Felicia used proactivity to denote her self-efficacious philosophy by saying:

If I don't study ahead of time, it means I will lag behind in my studies and it will be more difficult to understand my studies.

Bradley excelled because he was determined to achieve due performance. His experience is recounted as an emblem of self-efficacy:

I just checked my DP (Due Performance) and I passed all my modules. I had more than 30 in my DP's and 48 in maths. I got 35 in student skills. I got 40 in human development. I passed computer skills because we are not taking exams in it.

To Beatrice, self-efficacy pointed to absence of distraction because she did not have casual friends so as not to lose focus:

I am that kind of person who doesn't make friends because I don't want them to distract me. The friends that I have in class are those that I greet. I don't have friends that I visit so as to excel.

These were some of the experiences that pointed to determination, strong work ethic and discipline among the FSS, categorised under the umbrella of self-efficacy. 


\section{Discussion of findings}

The dynamics to which the FSS ascribed their abilities to cope with novel tenets at the academic institution hinged on the ambiance they experienced at school. The impact of uncompromising student-lecturer relationships, small class size and one-on-one consultation with students were likely responsible for their portrayal ofLOC. The FSS thus formed opinions on the grounds of these positive experiences and likely had control of their scholastic situations to learn. The positive and encouraging experiences at their disposal seemed to have given them the knack to put in effort to engage with learning activities. They saw a marked distinction between how they were assisted to learn in SA compared to the hostile behaviours of their lecturers back home. I argue that these experiences gave them the motivation to aspire to achieve, an indication of internal LOC to attain an identity. Furthermore I argue that the treatments given to them by their lecturers at the private academic institution in SA allowed them to take responsibility for their learning. Therefore I postulate that the development of academic identity is dependent on foreign students' capacity to demonstrate locus of control where student-lecturer relationships are fortified. Drawing on Zimbardo $(1985,275)$, the outcomes of actions by lecturers to engage with the students became contingent on how they facilitated learning to them. It therefore implies that learning facilitation in a non-coercive manner is capable of assisting students in developing academic identities to succeed and diminish dropout rate.

It thus seems as if LOC is an enhancer of the capacity of students to develop interest in schooling. I concur with Adeyemo's $(2005,166)$ opinion that the versatility of interest in whatever an individual does is significant. However in this paper, I add to Adeyemo's scholarship by arguing that having LOC is a stimulant to the development of interest in schooling to attain an identity. The positive experiences at the private academic institution likely predisposed the FSS to making what I refer to as informed choice. Their choices to remain at the academic institution was informed by the serenity of the school. Again, drawing on Adeyemo (2005), their choices were informed by the interests they developed by virtue of the LOC they had. The choices they made became their emblems of academic identity, drawing on Kohn's $(2002,155)$ scholarship. Using Hiddi's and Anderson's (1992) scholarship to analyse the interests of FSS. I argue that personal interests to become bilingual brought them to SA to study in English. I argue that PIis an emblem of intrinsic experiences at students' disposal.

Andre's story is a good starting point to discuss the importance of self-efficacy. He was determined to learn English within the shortest possible time available to him. He was a determined personality who believed in doing what needed to be done with rapt attention. His philosophy symbolised inherent self-efficacy to achieve when it was not easy to do so. Learning English was an ordeal as far as the FSS were concerned. It took guts to learn English in a short time. Proactivity was Felicia's style of efficacy, an attempt to keep abreast of scholarly matters beforehand. She believed this was her own way to be self-efficacious, her emblem of identity.Bradley was a determined personality. He shared his success, which was achieved through determination to succeed by breaking uneasy grounds. Having to learn English was his uneasy ground which did not deter him from excelling in his studies. Beatrice used focus as her philosophy by not having friends who could distract her from her studies. Her self-efficacy bordered on her inherent determination to succeed. It is obvious that the FSS saw their requirement to learn English as steppingstones to the accomplishment of their goals. Their experiences concur with Bandura's (1997) philosophy that individuals in possession of strong sense of efficacy trust in their capacity to undertake uneasy tasks. I add to Bandura's (1997) assertion that individuals with strong sense of self-efficacy overlook challenges because of their inherent ideologies to attain academic identity, which they perceive as yardsticks to make them succeed in their chosen enterprises.

The FSS participated with MKO in the communities of practice to attain an identity. They engaged with MKO comprising lecturers and peers in possession of academic offerings that led to their acquiescence with scholastic undertakings. They were able to step beyond individual territorial jurisdiction which mainly comprised academic knowledge acquired through French language to encapsulate the use of English to learn in the novel academic environment. It takes effrontery to learn in another language in the shortest possible time, an emblem of self-efficacy. I propose that the learning that the FSS underwent at the academic institution was likely as a result of inherent self-efficacy, brought about by their participation with MKO in communities of practice. Their experiences seem to support Shell et al.'s (1995) submission that self-efficacy entails selfassurance in one's capabilities to judiciously execute specific undertakings. Going by Schunk's (1991) definition of self-esteem as an individual's apparent ability and motivation to undertake assigned academic tasks, I argue that the engagement of new entrants with MKO in communities of practice is capable of producing the required dimension of academic identity to excel in learning.

\section{Conclusion and recommendation}

From the available evidence in this study, it becomes important to state that the development of academic identity is a complex phenomenon which depends on a number of internal and external factors experienced by FSSin the private academic setting. The ambiance in an academic environment is an important 
predictor of academic identity negotiation. The absence of discrimination at the private provider of higher education where this study was conducted created the ambiance that likely initiated the development of LOC among the FSS. The dynamics to which the FSS ascribed academic success was based on their perception of the experiences they had in the academic institution - a key ingredient in the development of LOC. Positive experiences with lecturers, peers and the school setting created the interest in them to continue to learn at the school. They made relevant choices that fell in line with the tenets of positive academic identity negotiation in the ACOP. These experiences were cemented by the inherent self-efficacy at their disposal intertwined with the initiatives they took to engage with MKO in the communities of practice. It may be vital to also state that LOC, interest in schooling and self-efficacy are capable of minimising dropout in higher education when stakeholders in communities of practice function within their jurisdictions by maintaining their association with one another for the common good of all stakeholders. It is recommended that academic institutions should be rid of discriminatory practices. Discriminatory practices are capable of hampering the development of LOC, interest in schooling and the development/exhibition of self-efficacy.These tendencies should be eradicated in higher education to reduce dropout. The mainstream South African society is noted for its xenophobic tendencies (Doodson, 2002). However, the private provider of higher institution is seen as a prototype of what the mainstream society should look like because of the absence of discrimination. It is not certain that the same operates in the public higher education institutions of South Africa after 20 years of freedom from the defunct apartheid regime. Recent studies have shown at the secondary school level that foreign students experienced discrimination (e.g. Vandeyar, 2011). This study gives a succinct idea of what operates in the private tertiary institution. I recommend that studies be conducted among foreign students in the South African public perspectives to know how they develop academic self-esteem. When this is done, we are afforded the opportunity to make comparative appraisal of these dynamics and their effects on foreign students. Furthermore we are able to know if we have been able to learn from the ills of the past. Learning positively from the ills of the past places this country in good stead to develop instead of disintegrating, especially as we get rid of discriminatory practices in the higher education sectors of SA.

\section{References}

[1]. Adebanji, C.A. (2013). Non-South African French-speaking students' curriculum experiences in a community of practice at a private tertiary institution. Unpublished doctoral thesis submitted to the University of South Africa.

[2]. Adeyemo, D. A. (2005). Parental Involvement, Interest in Schooling and School Environment as Predictors of Academic Selfefficacy among Fresh Secondary School Students in Oyo State, Nigeria. Electronic Journal ofPsychology of Education 5 (3): 1-15.

[3]. Bandura, A. (1997). Self-efficacy: The Exercise of Control. New York: W. H. Freeman.

[4]. Braun, V., \& Clarke, V. (2006). Using thematic analysis in psychology. Qualitative Research in Psychology, 3: 77-101.

[5]. Brown, L. (2008). The incidence of study-related stress in international students in the initial stage of the international sojourn. Journal of Studies in International Education, 12(1): 5-28.

[6]. Chapman, J. (1988). Cognitive-motivational characteristics and academic achievement of learning disabled children: a longitudinal study. Journal of Educational Psychology, 80: 357-365.

[7]. Doodson, B. (2002). "Gender and the brain drain". SAMP Migration Policy Series No. 23. Cape Town: SAMP.

[8]. Elo, S., \& Kyngas, H. (2008). The qualitative content analysis process. Journal of advanced nursing, 62(1): 107-115.

[9]. Kohn, T. (2002). Becoming an islander through action in the Scottish Hebrides. Journal of Royal Anthropological Institute (N.S.) 8: $143-158$.

[10]. Leung, C. (2010). A qualitative study of self-esteem, peer affiliation, and academic outcome among low achieving students in Hong-Kong. New horizons in education, 58(1): 22-42.

[11]. Marsh, H., Bryne, B., \& Yeung, A. (1999). Causal ordering of academic self-concept and achievement: reanalysis of a pioneering study and revised recommendations. Educational Psychologists, 34: 155-167.

[12]. Njus, D.M., \& Brockway, J.H. (1999). Perceptions of Competence and Locus of Control for positive and negative outcomes. Personality and individual differences 26: 531-548.

[13]. Otten, M. (2009). Academicus Interculturalis? Negotiating interculturality in academic communities of practice. Intercultural Education, 20(5): 407-417.

[14]. Owens, T. J. (2003). "Self and Identity." Pp. 205-32 in John Delamater, ed., Handbook of Social Psychology. New York: Kluwer Academic/Plenum Publishers.

[15]. Renninger, K.A. (2000). How Might the Development of Individual Interest contribute to the conceptualisation of intrinsic motivation? In: C. Sansome \& J.M. Harackiewicz (Eds.). Intrinsic and Extrinsic motivation: The Search for optimal motivation and performance. New York: Academic Press.

[16]. Reyes, R. (2007). A collective pursuit of learning the possibility to be: The CAMP experience assisting situationally marginalized Mexican American students to a successful student identity. Journal of Advanced Academics, 18(4): 618-659.

[17]. Reynolds, A. L., \& Constantine, M. G. (2007). Cultural adjustment difficulties and careerdevelopment of international college students. Journal of Career Assessment,15(3): 338-350.

[18]. Schunk, D.H. (1991). Self-efficacy and academic motivation. Educational Psychologist 26: 207-213.

[19]. Shell, D., Bruning, R. \& Colvin, C. (1995). Self-Efficacy, Attribution, and Outcome Expectancy Mechanisms in Reading and Writing Achievement: Grade-Level and Achievement-Level Differences. Journal of EducationalPsychology 87(3): $386-398$.

[20]. Tella, A., Tella, A.,\& Adeniyi, S.O. (1999). Locus of control, interest in schooling and self-efficacy as predictors of academic achievement among junior secondary school students in Osun State, Nigeria. New Horizons in Education, 59(1): 25-37.

[21]. Vandeyar, S. (2008).Changing Student-Teachers' Beliefs and Attitudes in South African Classrooms, 113-126. In Weber, E. (Eds.) 2008. Educational Change in South Africa: reflections on local realities, practices and reforms. Sense Publishers.

[22]. Vandeyar, S. (2010). Shifting selves: Constructing and negotiating academic identities. South African Journal of Higher Education, 24(6), 914-934. 
Locus of control, interest in schooling and self-efficacy as predictors of academic identity in .....

[23]. Vandeyar, S. (2011). Immigrant students' shifting identifications in South African schools. Int. J. Educ. Dev., doi:10.1016/j.ijedudev.2011.03.006

[24]. Williamson, K. (2006). Research in constructivist frameworks using ethnographic techniques. Library Trends, 55(1): 83101.

[25]. Zimbardo, P. G. (1985). Psychology and Life. Glenview, IL: Scott Foreman and Company.

[26]. Zimmerman, B. (2000). Self-Efficacy: An Essential Motive to Learn. Contemporary Educational Psychology 25(1): 82-91. 